\title{
DIRECTIONS FOR IMPROVING ANTI-CORRUPTION EDUCATION AND TRAINING OF FUTURE LAWYERS
}

\author{
Mikhail Smirnov $^{1^{\star}}$, Larisa Monakhova ${ }^{2}$ \\ ${ }^{1}$ Assoc. Prof. Dr., Mari State University, Russia, micsha.smi2015@yandex.ru \\ ${ }^{2}$ Assoc. Prof. Dr., Mari State University, Russia, laranka@mail.ru \\ ${ }^{*}$ Corresponding Author
}

\begin{abstract}
Corruption, being a negative social phenomenon, has acquired the character of a large-scale expansion over the past decades, and the trend towards strengthening its systemic nature is clearly evident.

Increased attention on the part of the state to the problem of corruption, the discovery of efficient solutions aimed at successful control of this phenomenon at the level of modernization of preventive measures makes the need to turn to the study of the potential of science in this area up to date.

In the Russian Federation, there are many problems in the field of corruption control in the system of state power and local self-government bodies. First of all, the problems relate to the imperfection of legal regulation.

While training lawyers, higher education institutions contribute to meeting the needs of the state for observing the principles of legality. This activity is directly associated with high risks (of a corrupt nature), which shows a clear need for special professional training of students to control corruption. In this regard, the analysis of lawyers' role in corruption control within the system of state power and local selfgovernment bodies is made up to date. At the same time, the priority is given to such issues as stereotypes of corruption perception by future lawyers, legal consciousness of lawyers as one of the conditions for ensuring law and order in corruption control, opportunities for improving anti-corruption education and training of future lawyers.
\end{abstract}

Keywords: Corruption control, anti-corruption, professional self-consciousness of lawyers, legal consciousness.

\section{INTRODUCTION}

Corruption is one of the most serious problems that all states face today. Despite numerous efforts to combat corruption and the fact that a large number of high-ranking officials and politicians have been convicted of corruption, the dynamics of related crimes is not favorable. In this regard, the legal consciousness is what restrains the destructive instincts.

According to O.A. Kovaleva and P.A. Stasenkov, there is a very important condition for raising the level of legal consciousness in the context of corruption control which is the expansion of legal knowledge, constant anti-corruption propaganda through media and social networks, and, most importantly, the establishment of an educational ideology for the development of legal culture from the school age [2, P. 3617].

When considering the issues related to corruption control, in order to form a high-level legal culture, it is necessary to form legal consciousness; to know the laws and rights; not to remain indifferent to the violation of the law and to demand its execution. 
A fundamental requirement for supporting the supremacy of statute law is that lawyers play a leading role in this process. Without reliable lawyers, there will be no supremacy of statute law as lawyers have a strong sense of justice. The lack of trustworthy lawyers to carry out the mission of maintaining the supremacy of statute law is an obstacle to the eradication of corruption [3, P. 261].

Crucial importance in corruption control is given to high-quality training of the corrsponding reserve of legal personnel who possess the appropriate level of legal consciousness, along with qualifications, culture (both in legal and ethical aspects), and experience.

This is due to the fact that "it is legal consciousness that belongs to one of the most important determinants of the formation of social and legal reality" [4, P. 90].

In this regard, it is very important to support lawyers, as well as students in the relevant areas, to come to an understanding that legal acts serve as a necessary and universal form of public relations.

Legal consciousness of lawyers, which is one of the key conditions for ensuring law and legal order in the corruption control, is a set of their views on how the laws are interpreted, perceived, evaluated, and implemented [5, P. 171].

Based on this understanding, we can distinguish two basic levels of reflection of lawyer's legal consciousness.

The first level corresponds to the scientific legal consciousness. This level provides the most adequate reflection of reality in the legal field. At the same time, we are talking about a complex ("summarized") position of expert lawyers based on verified statistical data. Thanks to the scientific legal consciousness of lawyers as an indispensable condition for ensuring law and legal order in corruption control, it is possible to carry out a gradual change for the better of the legal situation in the Russian Federation.

The second level corresponds to professional legal consciousness. In this case, we are talking about practicing professional personnel, whose activities are unthinkable without a formed legal consciousness. Lawyers form a rather complex and multi aspect value system, a set of priorities in order to separate legal realities from their opposites. Lawyers can estimate the benefits or harms of specific actions through professional legal consciousness.

\section{PURPOSE}

A large number of works have been devoted to issues related to corruption control in Russia. Modern research is directed at clarifying the concept of "corruption", the cause-and-effect links inherent in this phenomenon. A lot of papers are also devoted to the issues of anti-corruption policy and its peculiarities in Russia. A lot of works contain an analysis of the lawyer's role in corruption control in the system of state power and local self-government bodies.

At the same time, it should be noted that a fairly small number of modern papers are devoted to the study of stereotypes of corruption perception by future lawyers.

The purpose of the study is to prove the role of a lawyer in corruption control in the system of state power and local self-government bodies and to develop the recommendations for improving anti-corruption education and training of future lawyers. This goal is achieved due to the problem analysis of legal regulation of corruption control in the system of state power and local self-government bodies; the analysis of corruption perception stereotypes by future lawyers; the examination of issues related to legal consciousness of lawyers as one of the conditions for law and order enforcement in the corruption control; the study of ways to improve anti-corruption education and training of future lawyers.

\section{MATERIALS AND METHODS}

The empirical basis of the study was the statistical data of the international organization "Transparency International" and the results of student survey for future lawyers.

The subject of the research is theoretical and methodological approaches aimed at improving the anticorruption education and training of future lawyers. This was facilitated by general scientific methods (structural and functional, dialectical), as well as theoretical methods (analysis of scientific publications, analysis of the regulatory framework corresponding to the research topic). In addition, the authors used such methods as retrospective analysis, observation, modeling (related to educational situations), and statistical data analysis. 


\section{RESULTS AND DISCUSSION}

In the current social and economic conditions of Russian society, corruption has a systemic character, but, on the one hand, it is perceived as an immoral and unprincipled phenomenon, and, on the other hand, it serves as a comprehensive and effective means to solve a number of problems when the problem affects the relationship between citizens and state structures.

Many researchers believe that it is worth starting the corruption control by establishing a certain system of education for young people (directed against corruption). This should correspond to the value orientations on ethical and legal norms.

At the same time, it is important to take into account that among young people there are oppositional processes of association (considering corruption as an absolute evil) and dissociation (recognizing the permissibility or even desirability of corruption). What's more, while associative phenomena are widely discussed in society, dissociative processes are rarely discussed in public. In public consciousness, there is an established that corruption allows solving life problems where the laws do not work or these laws work against people.

According to the fair remark of I.V. Godunov and S.M. Nikolaev, "anti-corruption education should become an important part of legal education, along with instruction in law, in order to sharply reduce the moral and legal space in which dissociative processes of corruption renewal occur; this should happen through transfer, accumulation and assimilation of both knowledge and values to form respect for legal norms among future lawyers" [1, P. 173].

Therefore, in the current conditions, anti-corruption education should become a legal mission - the most important target part of higher legal education, since it reflects the most important idea of improving legal education to train lawyers in the close connection of academic legal science with practice, it should preserve and develop moral and ethical standards in professional activity. However, this mission is either not published in many law schools, or does not prescribe anti-corruption education.

The ability of corruption control is one of the most important requirements for the professional training of lawyers, which allows them to carry out their activities in conditions of increased corruption risks. For greater universality, the qualification requirements for lawyers in the framework of preventive training for anti-corruption activities can be classified into the following levels:

- A set of basic requirements that directly relate to compliance with the principle of law and order (it is about moral and ethical norms based on universal and professional morality);

- A set of special requirements that are imposed on public officials who carry out their activities in conditions of high corruption risks (primarily, this regards to the position of intolerance to corruption manifestations, the implementation of a list of duties, various prohibitions and restrictive measures to prevent corruption).

Many researchers note the necessity and demand for special legal training of students-future lawyers in the process of forming their competence in the field of corruption control.

To achieve the formation of the competence among future lawyers in the field of corruption control, it is necessary to observe the following pedagogical principles: complexity (solving problems in the relationship of the subjects of society: family, school, university, society, mass media, including the Internet); systemacity (there should be no campaigns, but a constant routine work should be carried out); timeliness of the pedagogical measures taken; sufficiency of pedagogical influence during classroom-based and extracurricular activities in the process of forming competence in the field of corruption control among students; individualization and consideration of psychological characteristics of the individual.

For students studying in the major "Legal Profession", it is important to understand that the problem of forming their competence in the field of corruption control is relevant today at the global level. Initially, this emerges from the UN goals and objectives. In modern realities, the UN, as well as various international bodies and organizations (UNESCO), have become the coordination centers of the international community and international public institutions in solving the problem of corruption rejection as a phenomenon, the formation of an anti-corruption culture. It should be noted that this applies not only to the activities at the international level, but also to work within states themselves. The UN assists not only to the development and approval of legal acts on corruption control, but also to the formation of a standard of educational programs aimed at developing competence in the field of corruption control.

In the process of developing competence in the field of corruption control, students-future lawyers have 
the following tasks: qualitative acquirement of knowledge on anti-corruption topics; mastering legal competencies and applying them in the process of not only professional activity, but also in everyday life; formation of an anti-corruption world-view among students; formation of anti-corruption beliefs.

\section{CONCLUSION}

The research analyzed the stereotypes of corruption perception by future lawyers. In respect to corruption, stereotyping is characterized by the identification of three groups of stereotypes: stereotypes regarding the acceptance or rejection of corruption; stereotypes concerning "patience" for "light" types of corruption; and stereotypes related to the incurability of corruption. The analysis carried out led to a general conclusion that the students-future lawyers demonstrate a fairly complete understanding of what should be attributed to corruption phenomena, how it is advisable to act in specific cases. Students have very significant attitudes regarding the corruption control. It is pertinent to note that in their conclusions modern student youth demonstrates a set of stereotypes inherent in mass consciousness.

The article determines legal consciousness of lawyers as one of the conditions for ensuring law and legal order in corruption control. It concludes that legal consciousness of a lawyer is characterized not only by a formal idea of various legal norms, but by a detailed understanding, an assessment of the meaning of these norms, a correct understanding of their targets, conditions of activity, and a list of tasks to be solved. In comparison with legal consciousness and legal culture of a person who does not have special knowledge in the legal field, legal consciousness of lawyers and their legal culture correspond to a higher level, since this is determined by the requirements of their professional activities, as well as the complex of duties assigned to lawyers. At combatting corruption lawyers are an important human resource because they act as key factors in the legal system. In this context, a high-quality training of a corresponding pool of legal personnel who have an appropriate level of legal consciousness, along with qualifications, culture (both in legal and ethical aspects), and experience is of decisive importance in corruption control. It is legal consciousness that belongs to one of the most important determinants of the formation of social and legal reality.

The study considered the directions of improving anti-corruption education and training of future lawyers.

One of the priority directions in the development of legal education and legal science is to ensure a close connection between the educational process and law enforcement practice through the development of clinical legal training.

Moreover, a very important area of improving anti-corruption education and training of future lawyers is the activities of project and training laboratories for anti-corruption policy.

The article considered the proposals regarding the systematization of the structure of training studentsfuture lawyers for anti-corruption activities, the formation of competencies on corruption control at a law faculty. Special attention is paid to the model of formation of competence among students-future lawyers in the field of corruption control, which is built according to the block principle, while providing for the basic structural elements of legal training. This refers to the following blocks: a block with an emphasis on motivation and targets; a cognitive block dealing with cognition issues; a block considering organizational issues, and a block describing the value-activity aspects.

\section{REFERENCE LIST}

1. Godunov, I.V. Theoretical justification of professional training of students for anti-corruption activities / I.V. Godunov, S.M. Nikolaev // Corruption crime control: problems and solutions. Proceedings of the International cientific and practical round tables held at I. Kant Baltic Federal University. - Kaliningrad, 2019.

2. Kovaleva, O.A. Topical issues of the need to form anti-corruption legal consciousness among law students / O.A. Kovaleva, P.A. Stasenkov // University complex as a regional center of education, science and culture. Proceedings of the All-Russian Scientific and Methodological Conference. - Orenburg, 2019.

3. Lodkin, A.E. Legal consciousness of future lawyers as one of the conditions for ensuring the rule of law and law and order in corruption control / A.E. Lodkin, N.V. Dryannykh // Social and political sciences. 2018. - No. 5. 
Proceedings of SOCIOINT 2021 8th International Conference on Education and Education of Social Sciences 14-15 June, 2021

4. Titarenko, T.A. Building Lawyers' Legal Consciousness and Culture / Т.А. Титаренко // Psychopedagogy in Law Enforcement. - 2018. - No. 4 (75).

5. Titova, N.K. The general doctrine about sense of justice. Professional sense of justice in legal activities / N.K. Titova // Education and law. - 2016. - No. 3. 